\title{
Design and Control of Boost Converter for Renewable Energy Sources
}

\author{
S.Subhashini ${ }^{1}$, C.Sankari ${ }^{2}$ \\ ${ }^{I}$ M.E Scholar, Department of Electrical and Electronics Engineering, Dr.Sivanthi Aditanar College of \\ Engineering, Tiruchendur. \\ ${ }^{2}$ Assistant Professor, Department of Electrical and Electronics Engineering, Dr.Sivanthi Aditanar College of \\ Engineering, Tiruchendur.
}

\begin{abstract}
In this paper, A Three phase AC/DC Boost Converter is presented for efficient transfer of energy from an irregular input power source to a battery storage device or a DC link. Circuit model for a three-phase boost converter is developed using the method of averaging, followed by a derivation of the conditions under which the pulse width modulated switching circuit exhibits a resistive behavior from the input. Based on the circuit model obtained, the range of the duty cycle can be calculated. The gate pulse can be generated according to the switching states of MOSFETs. Feedback control is used to regulate the phase-to-phase input resistances of the circuit to desired values. The maximum power can be transferred from variable input source to battery or dc link, so this can be applicable for low speed wind turbines, wave energy converter \& mechanical vibrations which having time-varying profiles.
\end{abstract}

Keywords: $A C-D C$ power converters, power conversion, pulse width modulation, unbalanced source

\section{Introduction}

Three phase power electronic converters are required in renewable generation systems such as variable speed wind and marine wave energy. In these renewable energy systems, the kinetic energy of the device is converted into stand-alone or grid-connected electricity through three phase synchronous or induction generators and power electronics interfaces. The intermittent characteristic of the above energy resources results in generated power profiles with time-varying voltages and currents whose amplitudes and frequencies are subject to random variations. Dynamically stable and efficient energy flow in these systems requires the use of advanced power controllers that can adapt to the dynamic characteristics of the source and load. Traditional ACDC converters using diodes and thyristors to provide energy flow have issues including poor power quality, voltage distortion, and poor power factor [1]-[4].

Among the proposed topologies, three-phase boost/buck converters are utilized in energy conversion involving random sources of power as they can offer high efficiency and low electromagnetic interference emissions [5], [6]. Performance criteria of these converters are highly dependent on the control strategy used. To improve the performance of pulse-width-modulated (PWM) boost/buck converters toward ideal power quality conditions, different control strategies have been presented using space vector modulation [7], soft switching [8], sliding mode [9], and nonlinear and adaptive control methods [10], [11]. The above methods have been utilized in applications such as speed drives and power supplies for telecommunications equipment in which the mains supply is the input power source with a relatively fixed amplitude and frequency. These approaches have mainly assumed the circuits to be in the sinusoidal steady state, which cannot be applied to applications involving random sources of power with transient power profiles such as wind, wave, and mechanical vibrations.

To achieve maximum power transfer in renewable energy converters including wind [12] and wave is to adjust the apparent electric load of the generator through an appropriate controller using power electronics. In this paper, we utilize the three-phase boost rectifier topology that can enforce a resistive characteristic at the inputs of the converter. The resistive input behavior can greatly reduce harmonic components and improve power quality when compared to other topologies that are dependent on the operating point and suffer from a lagging power factor at the fundamental frequency. Hence, the controller can convert band-limited waveforms with multiple input frequencies and amplitudes into dc power by regulating the phase-to-phase input resistances to desired values.

\section{II .Three Phase AC/DC Boost Converter}

A Three phase AC/DC Converter is a power electronics device that transfers energy from an irregular input power source to a battery storage device or a DC link. A circuit model for a three phase boost converter is developed using the method of averaging, based on the circuit model a phase to phase resistance can be evaluated. To achieve maximum power absorption in such cases, the provided embodiments utilize a variable 
resistive behavior across each phase of the converter. A condition for maximum extraction of the average power is obtained for a wave energy converter, which suggests operation under the resonance condition with a resistive behavior seen by the generator. An effective way of achieving the maximum power transfer is to adjust the apparent electric load of the generator through an appropriate controller using a power electronics interface. The converter does not require a priori knowledge of the input waveform characteristics, such as frequency or amplitude. Furthermore, it can convert band-limited waveforms with multiple input frequencies and amplitudes by exhibiting desired input resistances at the three-phase source input based on desired set-points that can be varied during operation.

\section{A.Design of boost converter} steps of:

A method for converting an irregular power signal into an optimal DC power signal comprising the

(a) Providing a three-phase boost converter circuit comprising:

(i) An input

(ii) An output

(iii) A pulse-width modulated (PWM) switching circuit.

(b) Providing an irregular power signal to the input of the three-phase boost converter circuit

(c) Adjusting the resistance applied to each phase of the three-phase boost converter.

The block diagram of three phase ac-dc bridgeless boost converter is shown in following figure.

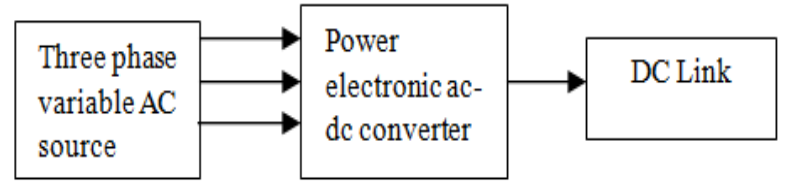

Fig.1. Block Diagram of three phase AC/DC Converter

The circuit can be designed to provide purely active power conversion of a band-limited input voltage source to a DC load. The performances of a power electronic converter are presented. Representative applications are related to a small scale wave energy converter and a regenerative mechanism to convert vibration energy in vehicular suspension into battery charge. The irregular power signal does not have at least one of the following: a sinusoidal steady state, fixed amplitude, or a fixed frequency. The pulse generator is configured to control an ON/OFF state of individual switches in the PWM switching circuit to achieve a desired resistance in the PWM switching circuit.

The PWM switching circuit comprises three switches configured to switch between ON and OFF states, and wherein during at least one step of the method a first switch is allowed to switch between ON and OFF states, and a second switch and a third switch are not allowed to switch between ON and OFF states, thereby increasing power efficiency by reducing switching power loss. The results indicate that unity power factor operation for irregular and time-varying inputs is achievable through a feedback controller with the capability to change resistive input behavior based on desired set-points. The converter can thus be used in various applications requiring real-time change of desired input resistance to control and optimize the energy flow to a DC link (e.g., in order to generate energy from renewable energy sources).

\section{Operating Principle \& Circuit analysis}

The three-phase bridge-less boost converter is illustrated in Fig.2 Compared to a conventional boost rectifier, one diode is eliminated from the line-current path, resulting in reduced conduction losses. Also, Scotty diodes and MOSFETs are used to achieve low conduction losses. Furthermore, to reduce switching losses, only one MOSFET is allowed to switch at each time instant, while the other two are kept on/off, depending on the relative voltages of the corresponding phases. 


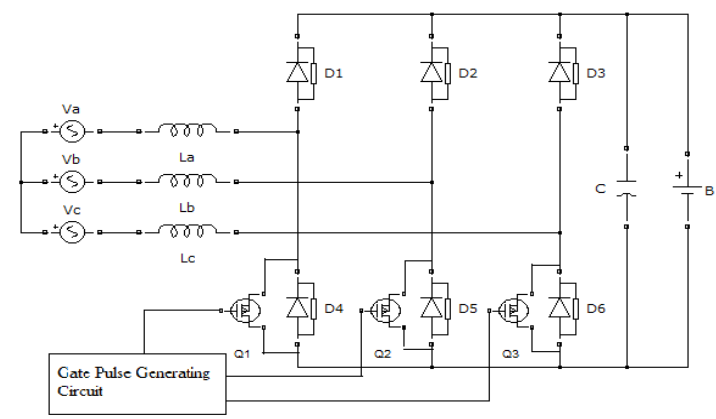

Fig.2.Three-phase bridgeless boost-type rectifier

The three-phase bridgeless boost converter is shown in Fig.2. Compared to a full-bridge converter, the efficiency of these converters can be improved by $8 \%-10 \%$, especially for low-power applications. Furthermore, to reduce the switching losses, only one MOSFET is switched at each time instant, while the other two are kept $\mathrm{ON} / \mathrm{OFF}$ depending on the relative voltages of the corresponding phases. In the following, we provide a brief review of the circuit operation followed by a derivation of the nonlinear resistances seen by the input sources using the averaging method. The corresponding phase-to-phase voltages $V_{i j}(t)$ defined as follows

$$
V_{i j}(t)=V_{i}(t)-V_{j}(t), \quad i, j=a, b, c ; \quad i \neq j
$$

In the following, a brief review of the circuit operation is provided, followed by a derivation of the nonlinear resistances seen by the input sources $\mathrm{V}_{\mathrm{a}}, \mathrm{V}_{\mathrm{b}}$, and $\mathrm{V}_{\mathrm{c}}$ using an averaging method. Let us consider a typical case when $V_{a b} \geq 0, V_{a c} \geq 0$, for which $Q_{1}$ is switching in the ON/OFF mode while $Q_{2}$ and $Q_{3}$ are kept ON.

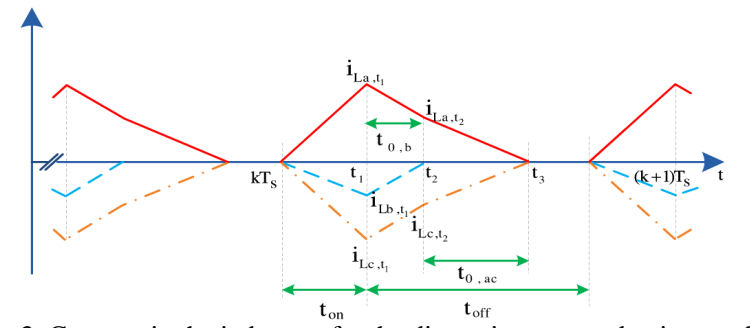

Fig.3. Currents in the inductors for the discontinuous conduction mode

The currents of inductors are shown in Fig.3 which illustrates the charging and discharging of the inductors in each operating mode. It is worth noting that the converter along with the controller is operated in the discontinuous conduction mode (DCM). The operating modes are next analyzed in the following.

\section{A. Mode1:Q1, $Q 2$, and $Q 3$ are on $\left(k T_{S} \leq t \leq t 1\right)$}

In this mode of operation all switches are kept ON. When all switches are ON, none of the diodes D $1-\mathrm{D}_{3}$ can conduct. In this case, the inductor current of each phase builds up and the energy captured from the input sources is stored in the magnetic fields of the inductors. We denote this case as mode 1 of operation of the circuit.

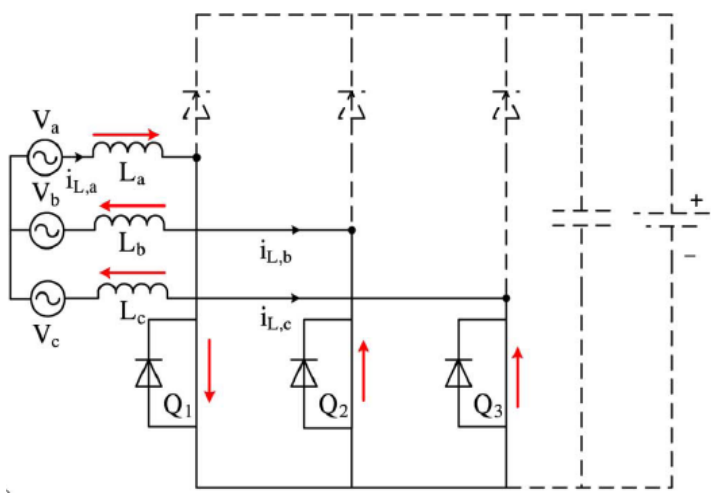

Fig.4. Mode1 of circuit operation when Q1, Q2, and Q3 are all ON 


\section{B. Mode2: $Q_{1}$ and $Q_{2}$ are turned off, and $Q_{3}$ is kept on $\left(t_{1} \leq t \leq t 2\right)$}

Switch $\mathrm{Q}_{1}$ is turned off, $\mathrm{Q}_{2}$ is turned off and $\mathrm{Q}_{3}$ is kept on as long as $\mathrm{V}_{\mathrm{bc}}>0$. Similarly, when $\mathrm{V}_{\mathrm{bc}}<0, \mathrm{Q}_{3}$ is turned off and $\mathrm{Q}_{2}$ is kept on. For the case when $\mathrm{V}_{\mathrm{bc}}=0$, both $\mathrm{Q}_{2}$ and $\mathrm{Q}_{3}$ are kept on.

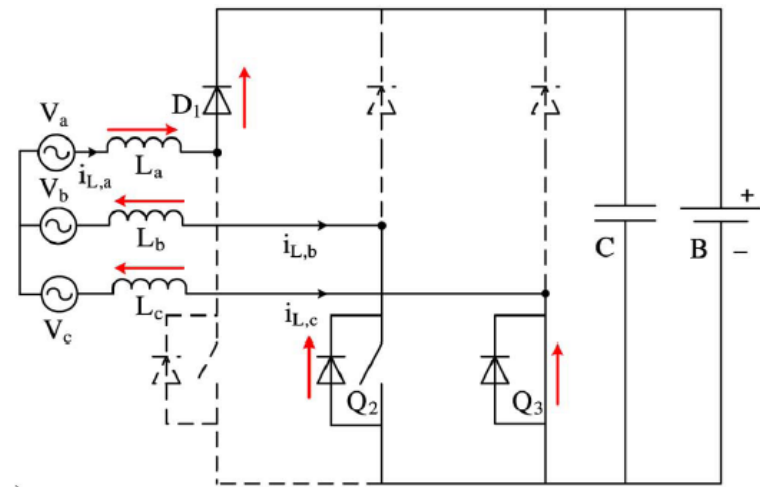

Fig.5. Mode2 of circuit operation when $\mathrm{Q} 1$ and $\mathrm{Q} 2$ are $\mathrm{OFF}$ and $\mathrm{Q} 3$ is $\mathrm{ON}$

Next let us consider mode 2 of operation of the circuit as follows. Assuming $\mathrm{V}_{\mathrm{bc}}>0$, current flows through diode $\mathrm{D}_{1}$, load, and back through the anti-parallel diode of $\mathrm{Q}_{2}$ and $\mathrm{Q}_{3}$, as depicted in Fig.2. In this case, the stored energy in the inductors together with the energy coming from the input sources charges the battery. This condition is continued until $\mathrm{i}_{\mathrm{Lb}}$ reaches zero.

C. Mode 3: Q1 and Q2 Remain off and Q3 is Kept on until $i L b=0(t 2 \leq t \leq t 3)$

In mode 3 , the remaining stored energy in $L_{a}$ and $L_{c}$, along with the energy coming from $v_{a}$ and $v_{c}$, charge the battery until the inductors are totally discharged.

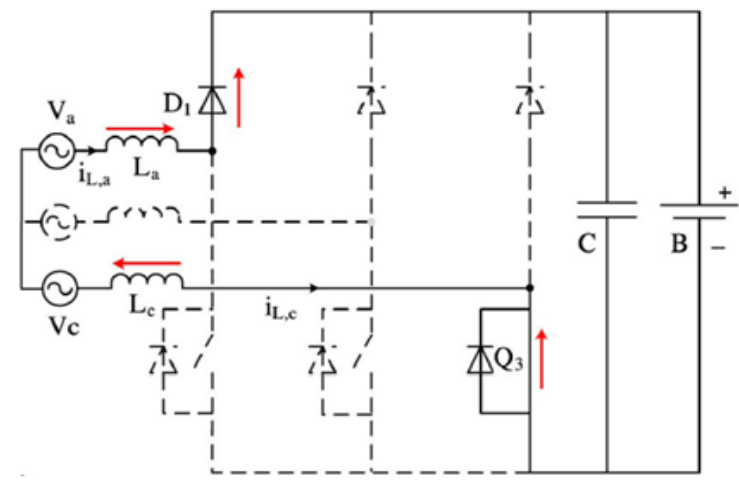

Fig.6. Mode 3 of circuit operation when Q1 and Q2 are OFF, Q3 is ON, and the inductor current of phase b reaches zero (iLb= 0)

\section{Switching States of three modes}

Table. I summarize the above modes of operation with all possible arrangements of phase-to-phase voltages. From this table, it is evident that the switches are all $\mathrm{ON}$ in mode 1 regardless of the phase-to-phase voltages. As soon as one of the switches is turned OFF, the states of other switches are changed according to the corresponding phase-to-phase voltages.

TABLE.I

States Of Switches Q1, Q2, AND Q3 For Different Modes OF Operation

\begin{tabular}{|c|c|c|c|}
\hline Phase-to-phase voltages & $\mathrm{Q}_{1}$ & $\mathrm{Q}_{2}$ & $\mathrm{Q}_{3}$ \\
\hline Any combination of voltages & ON & ON & ON \\
\hline $\mathrm{V}_{\mathrm{ac}} \geq 0, \mathrm{~V}_{\mathrm{bc}} \geq 0$ & OFF & OFF & ON \\
\hline $\mathrm{V}_{\mathrm{ab}} \geq 0, \mathrm{~V}_{\mathrm{cb}} \geq 0$ & OFF & ON & OFF \\
\hline $\mathrm{V}_{\mathrm{ba}} \geq 0, \mathrm{~V}_{\mathrm{c} a} \geq 0$ & ON & OFF & OFF \\
\hline
\end{tabular}




\section{A. $\operatorname{Mode1}\left(k T_{S} \leq t \leq t 1\right)$}

\section{DERIVATION FOR THREE MODES}

In this mode of operation, all MOSFET switches $Q 1, Q 2$, and $Q 3$ are kept $\mathrm{ON}$ as shown in Fig.4. By utilizing the Kirchhoff's circuit laws and performing some algebraic manipulations in each switching interval, we have the currents in the inductors at $\mathrm{t}=\mathrm{t} 1$ are given by

$$
\begin{aligned}
& i_{L a}\left(t_{1}\right)=i_{L a, t 1}=(1 / 3 L)\left(V_{a b}+V_{a c}\right) t_{o n} \\
& i_{L b}\left(t_{1}\right)=i_{L b, t 1}=(-1 / 3 L)\left(2 V_{a b}-V_{a c}\right) t_{o n} \\
& i_{L c}\left(t_{1}\right)=i_{L c, t l}=(-1 / 3 L)\left(2 V_{a c}-V_{a b}\right) t_{o n} .
\end{aligned}
$$

Let us assume that the switching frequency is chosen to be much higher than the frequency content of input source. Hence, $\mathrm{V}_{\mathrm{ij}}$ is approximately constant during $\mathrm{t}_{\mathrm{on}}$, i.e. $\mathrm{V}_{\mathrm{ij}}(\mathrm{t})=\mathrm{V}_{\mathrm{ij}}\left(\mathrm{kT}_{\mathrm{s}}\right)$. For simplicity, it is also assumed that the values of all the three inductors are equal to $\mathrm{L}$, i.e., $\mathrm{La}=\mathrm{Lb}=\mathrm{Lb}=\mathrm{L}$.

\section{B. $\quad$ Mode $2(t 1 \leq t \leq t 2)$}

In this mode of operation, when the switches are turned OFF, the stored energy in the inductors together with the energy coming from the input sources charge the battery as shown in Fig.5. As in Mode 1, using Kirchhoff's circuit laws and performing some algebraic manipulations in each switching interval, the currents through the inductors can be obtained as follows

$$
\begin{aligned}
i_{L a}(t)= & i_{L a, t 1}+(1 / 3 L)\left(V_{a b}+V_{a c}\right)(t-t 1) \\
& -(2 / 3 L)\left(V_{B}+V_{D}\right)(t-t 1)
\end{aligned}
$$

Where $V_{B}$ stands for the battery voltage and $V_{D}$ represents the voltage drop across diode D1. Again, $V_{i j}(t)$ is assumed to be approximately constant during $\mathrm{t}_{\mathrm{off}}$. Substituting (2) into (3) and setting $\mathrm{i}_{\mathrm{Lb}}\left(\mathrm{t}_{2}\right)=0$ results in

and

$$
i_{L a, t_{2}}=-i_{L c, t_{2}} \frac{1}{L} \frac{\left(V_{a c^{-}} V_{a b}\right)\left(V_{B}+V_{D}\right) t o n}{V_{B}+V_{D}-2 V_{a b}+V_{a c}}
$$

$$
t_{0, b}=\frac{\left(2 V_{a b}-V_{a c}\right) t o n}{V_{B}+V_{D}-2 V_{a b}+V_{a c}}
$$

C. Mode $3(t 2 \leq t \leq t 3)$

When $\mathrm{i}_{\mathrm{Lb}}$ reaches zero, the rest of the stored energy in the magnetic fields of $\mathrm{L}_{\mathrm{a}}$ and $\mathrm{L}_{\mathrm{c}}$, along with the energy drawn from the corresponding input sources, charge the battery until the inductors get totally discharged as shown in Fig.6. Using a similar analysis for modes 1 and 2, we have

and

$$
\begin{aligned}
& i_{L a}(t)=i_{L a, t 2}+(1 / 2 L)\left(V_{a c}-V_{B}-V_{D}\right)\left(t-t_{2}\right) \\
& i_{L c}(t)=i_{L c, t 2}+(1 / 2 L)\left(V_{a c}-V_{B}-V_{D}\right)\left(t-t_{2}\right)
\end{aligned}
$$

$$
t_{0, a c}=\left(\frac{V_{a b}-V_{a c}}{V_{a c}-V_{B}+V_{D}}\right)\left(\frac{2 t_{o n}\left(V_{B}+V_{D}\right)}{V_{B}+V_{D}-2 V_{a b}+V_{a c}}\right)
$$

D. Derivation of Phase-to-Phase Resistances

The averaged instantaneous current in one switching cycle can be derived by using the inductor currents. Hence the instantaneous averaged phase-to-phase resistances as seen from the input sources. The total charge passing through the inductor of three phases is given by,

$$
\begin{aligned}
& \Delta q_{a}=(1 / 2)\left[i_{L a, t 1} t_{o n}+\left(i_{L a, t 1}+i_{L a, t 2}\right) t_{0, b}+i_{L a, t 2} t_{0, a c}\right] \\
& \Delta q_{b}=(1 / 2)\left[i_{L b, t 1} t_{o n}+i_{L a, t 1} t_{0, b}\right] \\
& \Delta q_{c}=(1 / 2)\left[i_{L c, t 1} t_{o n}+\left(i_{L c, t 1}+i_{L c, t 2}\right) t_{0, b}+i_{L c, t 2} t_{0, a c}\right]
\end{aligned}
$$

Where $\Delta \mathrm{q}_{\mathrm{j}}$ is the total charge passing through the inductor of phase $j, L j$ (where $j=a, b, c$ ), during the time interval $\mathrm{kTs} \leq \mathrm{t} \leq(\mathrm{k}+1) \mathrm{T}_{\mathrm{s}}$. By substituting (3), (5), (6), and (8) into (9), and after some algebraic steps, we have 


$$
\begin{aligned}
\Delta q_{a}= & \frac{t_{o n}^{2}}{6 L}\left(\frac{\left(V_{B}+V_{D}\right)}{V_{B}+V_{D}-2 V_{a b}+V_{a c}}\right)\left(V_{a b}+V_{a c}\right) \\
& -\frac{t_{o n}^{2}}{6 L}\left(\frac{\left(V_{B}+V_{D}\right)}{V_{B}+V_{D}-2 V_{a b}+V_{a c}}\right) n_{1}\left(V_{i j}, V_{B}, V_{D}\right) \\
\Delta q_{c}= & -\frac{t_{o n}^{2}}{6 L}\left(\frac{\left.V_{B}+V_{D}\right)}{V_{B}+V_{D}-2 V_{a b}+V_{a c}}\right)\left(2 V_{a c}+V_{a b}\right) \\
& +\frac{t_{o n}^{2}}{6 L}\left(\frac{\left(V_{B}+V_{D}\right)}{V_{B}+V_{D}-2 V_{a b}+V_{a c}}\right) n_{1}\left(V_{i j}, V_{B}, V_{D}\right)
\end{aligned}
$$

Where $\mathrm{ij}=\mathrm{ab}, \mathrm{ac}, \mathrm{bc}$ and the term $\mathrm{n}_{1}\left(\mathrm{~V}_{\mathrm{ij}}, \mathrm{V}_{\mathrm{B}}, \mathrm{V}_{\mathrm{D}}\right)$ is given by

Furthermore,

$$
n_{1}\left(V_{i j}, V_{B}, V_{D}\right)=\frac{3 V_{a c}\left(V_{a c}+V_{a b}\right)}{V_{a c}-V_{B}-V_{D}}
$$

$$
\Delta q_{b}=-\frac{t_{o n}^{2}}{6 L}\left(\frac{\left(V_{B}+V_{D}\right)}{V_{B}+V_{D}-2 V_{a b}+V_{a c}}\right)\left(2 V_{a b}+V_{a c}\right)
$$

It should be noted that all the above equations were derived by assuming that $\mathrm{i}_{\mathrm{Lb}} \leq \mathrm{i}_{\mathrm{Lc}}$. Performing a similar analysis for the case when $i_{L b}>i_{L c}$, we have

$$
\begin{aligned}
\Delta q_{a}= & \frac{t_{o n}^{2}}{6 L}\left(\frac{\left(V_{B}+V_{D}\right)}{V_{B}+V_{D}-2 V_{a c}+V_{a b}}\right)\left(V_{a b}+V_{a c}\right) \\
& -\frac{t_{o n}^{2}}{6 L}\left(\frac{\left.V_{B}+V_{D}\right)}{V_{B}+V_{D}-2 V_{a c}+V_{a b}}\right) n_{2}\left(V_{i j}, V_{B}, V_{D}\right) \\
\Delta q_{b}= & -\frac{t_{o n}^{2}}{6 L}\left(\frac{\left(V_{B}+V_{D}\right)}{V_{B}+V_{D}-2 V_{a c}+V_{a b}}\right)\left(2 V_{a b}+V_{a c}\right) \\
+ & \frac{t_{o n}^{2}}{6 L}\left(\frac{\left(V_{B}+V_{D}\right)}{V_{B}+V_{D}-2 V_{a c}+V_{a b}}\right) n_{2}\left(V_{i j}, V_{B}, V_{D}\right)
\end{aligned}
$$

Where $\mathrm{ij}=\mathrm{ab}, \mathrm{ac}, \mathrm{bc}$ and the nonlinear term $\mathrm{n}_{2}\left(\mathrm{~V}_{\mathrm{ij}}, \mathrm{V}_{\mathrm{B}}, \mathrm{V}_{\mathrm{D}}\right)$ is given by

and

$$
n_{2}\left(V_{i j}, V_{B}, V_{D}\right)=\frac{3 V_{a b}\left(V_{a b}+V_{a c}\right)}{V_{a b}-V_{B}-V_{D}}
$$

$$
\Delta q_{c}=-\frac{t_{o n}^{2}}{6 L}\left(\frac{\left(V_{B}+V_{D}\right)}{V_{B}+V_{D}-2 V_{a c}+V_{a b}}\right)\left(2 V_{a c}+V_{a b}\right)
$$

The non-linear terms $\mathrm{n} 1 \& \mathrm{n} 2$ are eliminated for our convenience. The average values of the currents in the inductors at instant $\mathrm{kTs}$ can then be written as

$$
i_{L j}=\Delta q_{j} / T_{s}, \quad j=a, b, c .
$$

Substituting (12) and (14) into (17) results in

Where

$$
2 V_{a b}-V_{a c}=-\frac{6 L T s}{t_{o n}^{2}}\left(1-\frac{V_{i n, b c}}{V_{B}+V_{D}}\right) i_{L b}+\check{S}_{b c} n_{2}
$$

$$
V_{i n, b c,}=\left(2-3 \check{S}_{b c}\right) V_{a b},-\left(1-3 \check{S}_{b c}\right) V_{a c}
$$

In which $\mathrm{S}_{\mathrm{bc}}$ is a control signal which can take values from the discrete set $\{0,1\}$ as follows:

$$
S_{b c}=1, i_{L b,} \leq i_{L c}, S_{b c}=0, i_{L b,}>i_{L c},
$$

Also, the term $\breve{\mathrm{S}}_{\mathrm{bc}}$ in (18) is the logical complement of $\mathrm{S}_{\mathrm{bc}}$ (e.g., $\mathrm{S}_{\mathrm{bc}}=0$ and $\breve{\mathrm{S}}_{\mathrm{bc}}$ are equivalent). Similarly, substituting (10) and (16) into (17), and using the control signal $S_{\mathrm{bc}}$, we have

$$
2 V_{a c}-V_{a b}=-\frac{6 L T s}{t_{o n}^{2}}\left(1-\frac{V_{i n, b c}}{V_{B}+V_{D}}\right) i_{L c}+\check{S}_{b c} n_{1}
$$

Solving (18) and (20) in terms of $\mathrm{V}_{\mathrm{ab}}$ and $\mathrm{V}_{\mathrm{ac}}$ results in 
and

$$
V_{a b}=-\left(\frac{4 K_{b c} L T s}{t_{o n}^{2}}\right) i_{L b}-\left(\frac{2 K b c L T s}{t_{o n}^{2}}\right) i_{L c}+\frac{1}{3}\left(S_{b c} n_{1}-\check{S}_{b c} n_{2}\right)
$$

Where,

$$
V_{a c}=-\left(\frac{2 K_{b c} L T s}{t_{o n}^{2}}\right) i_{L b^{-}}-\left(\frac{4 K b c L T s}{t_{o n}^{2}}\right) i_{L c}+\frac{1}{3}\left(S_{b c} n_{1}-\check{S}_{b c} n_{2}\right)
$$

$$
K_{b c}=1-\left(V_{i n, b c} / V_{B}+V_{D}\right) .
$$

Subtracting (22) from (23), we have

$$
V_{b c}=\frac{2 K_{b c} L T s}{t_{o n}^{2}} i_{L b c}+\frac{1}{3}\left(S_{b c} n_{1}-\check{\mathrm{S}}_{b c} n_{2}\right)
$$

Where $i_{L b c}=i_{L b}-i_{L c}$ Equation (24) indicates that, at each sampling time $t=k T s$, there exists a nonlinear resistance between two phases given by

$$
R_{b c}=\frac{2 L T s}{t_{o n}^{2}}\left(\frac{1-\left(2-3 \check{S}_{b c}\right) V_{a b}-\left(1-3 \check{S}_{b c}\right) V_{a c}}{V_{B}+V_{D}}\right)+r_{n, b c}
$$

Where $\mathrm{R}_{\mathrm{bc},}=\mathrm{V}_{\mathrm{bc}, \mathrm{k}} / \mathrm{i}_{\mathrm{Lbc}}$ and

$$
r_{n, b c}=\left(\frac{1}{3 \mathrm{i}_{\mathrm{Lbc}}}\right)\left(\mathrm{S}_{\mathrm{bc}} \mathrm{n}_{1}-\check{\mathrm{S}}_{\mathrm{bc}} \mathrm{n}_{2}\right)
$$

Similarly, $\mathrm{R}_{\mathrm{ab}}$ and $\mathrm{R}_{\mathrm{ac}}$ can be obtained as follows

$$
\begin{aligned}
& R_{a b}=\frac{2 L T s}{t_{o n}^{2}}\left(\frac{1-\left(2-3 \check{S}_{a b}\right) V_{c a}-\left(1-3 \check{S}_{a b}\right) V_{c b}}{V_{B}+V_{D}}\right)+r_{n, a b} \\
& R_{a c}=\frac{2 L T s}{t_{o n}^{2}}\left(\frac{1-\left(2-3 \check{S}_{a c}\right) V_{b a}-\left(1-3 \check{S}_{a c}\right) V_{b c}}{V_{B}+V_{D}}\right)+r_{n, a c}
\end{aligned}
$$

Where $S_{a b}$ and $S_{a c}$ are defined similar to $S_{b c}$, i.e.,

and

$$
\mathrm{S}_{\mathrm{ab}}=1, \mathrm{i}_{\mathrm{La}} \leq \mathrm{i}_{\mathrm{Lb}} ; \quad \mathrm{S}_{\mathrm{ab}}=0, \mathrm{i}_{\mathrm{La}}>\mathrm{i}_{\mathrm{Lb}}
$$

Furthermore,

$$
\mathrm{S}_{\mathrm{ac}}=1, \mathrm{i}_{\mathrm{La}} \leq \mathrm{i}_{\mathrm{Lc}} ; \quad \mathrm{S}_{\mathrm{ac}}=0, \mathrm{i}_{\mathrm{La}}>\mathrm{i}_{\mathrm{Lc}} .
$$

$$
\begin{aligned}
& r_{n, a b}=\left(\frac{1}{3 i_{L a b}}\right)\left(S_{a b} n_{1}-\check{S}_{a b} n_{2}\right) \\
& r_{n, a c}=\left(\frac{1}{3 i_{L a c}}\right)\left(S_{a c} n_{1}-\check{S}_{a c} n_{2}\right) .
\end{aligned}
$$

Similarly, the corresponding terms $\breve{\mathrm{S}}_{\mathrm{ab}}$ and $\breve{\mathrm{S}}_{\mathrm{ac}}$ are logical complements of $\mathrm{S}_{\mathrm{ab}}$ and $\mathrm{S}_{\mathrm{ac}}$, respectively. It is worth noting that $R_{a c}=R_{c a}, R_{a b}=R_{b a}$, and $R_{b c}=R_{c b}$. Due to the resistive nature of (24)-(26), there is no phase difference between the phase-to-phase voltages and corresponding currents, each phase-to-phase input resistance has a bias term, $r_{n, i j}$ and a nonlinear term which are compensated. The off-time of the switches must be large enough to let the inductors to be completely discharged.

Thus, we have

$$
\mathrm{t}_{0, \mathrm{~b}}+\mathrm{t}_{0, \mathrm{ac}} \leq \mathrm{t}_{\mathrm{off}}
$$

Also, $t_{\text {on }}$ and $t_{\text {off }}$ can be written in terms of the duty cycle $d$ of the PWM waveform as follows

$$
\mathrm{t}_{\mathrm{on}}=\mathrm{dT}_{\mathrm{s}} \mathrm{t}_{\mathrm{off}}=(1-\mathrm{d}) \mathrm{T}_{\mathrm{s}}
$$

Substituting (5), (7), and (28) into (27) and performing some algebraic manipulations, the condition to achieve resistive performance can be obtained as follows:

$$
\mathrm{d} \leq 1-\frac{\mathrm{V}_{\mathrm{ac}}}{V_{B}+V_{D}}
$$


The above relationship indicates that a pseudo-resistive behavior can be achieved at a duty cycle that is dependent on the ratio of the phase-to-phase input voltage and the sum of the voltage drop across the diode and battery.

\section{E. Pulse Generation}

The pulse generation is based on the switching states of different modes of operation. The block diagram of pulse generating circuit is shown in following figure.

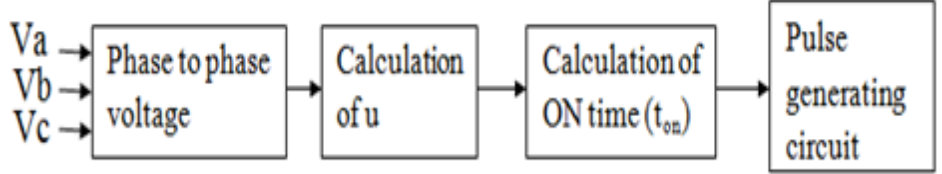

Fig.7. gate pulse generating circuit

Based on (24)-(26), the parameters that can affect the value of input resistances are $T_{s}$, $t$ on, and $L$. Thus, $t$ on is used to obtain the control input which can be related to $d$ for particular $T_{s}$. To this end, let us define r, $A$, and $y_{p q}$ as follows

$$
\begin{aligned}
& r=\frac{2 L T_{S}}{t_{o n}^{2}}, A=V_{B}+V_{D} \\
& y_{p q}=\frac{V_{i n, p q}}{i_{L p}}
\end{aligned}
$$

The values of $p, q$ are chosen based on the switching arrangements and phase-to phase voltages as described in (1). By utilizing (30) and the corresponding resistive relationships between phase's $p$ and $q$, i.e., (24)-(26), we have

Now, let us define

$$
y_{p q}=u\left(1-\frac{V_{i n, p q}}{A}\right)
$$

$$
u=\frac{y_{p q}}{\left(1-\frac{V_{i n, p q}}{A}\right)}
$$

From (30) and (33)

$$
\begin{aligned}
& \frac{2 L T_{S}}{t_{o n}^{2}}=\frac{y_{p q}}{\left(1-\frac{V_{i n, p q}}{A}\right)} \\
& \frac{1}{t_{o n}^{2}}=\frac{y_{p q}}{2 L T_{S}\left(1-\frac{V_{i n, p q}}{A}\right)} \\
& t_{o n}=\sqrt{\frac{2 L T_{S}\left(1-\frac{V_{i n, p q}}{A}\right)}{y_{p q}}}
\end{aligned}
$$

In summary, the switching arrangement is first set based on the phase-to-phase input voltages at each time instant. In pulse generating circuit, the gate pulse is generated by a PWM signal.

\section{A. Simulation of pulse generating circuit}

\section{V.SIMULATION AND EXPERIMENTAL RESULTS}

According to switching states of three switches a gate pulse can be generated. The time duration (ON and OFF time) can be controlled by this circuit. In mode 1operation all the switches are ON, when all switches are $\mathrm{ON}$, none of the diodes $\mathrm{D}_{1}-\mathrm{D}_{3}$ can conduct. In this case, the energy drawn from the input source is stored in the magnetic fields of the inductors. In mode 2 only one switch is ON at a time. In this case, the stored energy in the inductor $\left(i_{\mathrm{Lb}}\right)$ together with the energy drawn from the input sources is fed to the battery. In mode 3 , the remaining stored energy in $\mathrm{L}_{\mathrm{a}}$ and $\mathrm{L}_{\mathrm{b}}$ along with the energy coming from $\mathrm{V}_{\mathrm{a}}$ and $\mathrm{V}_{\mathrm{c}}$ charge the battery until the inductors is totally discharged.

The pulse generator is configured to control an ON/OFF state of individual switches in the PWM switching circuit to achieve a desired resistance in the PWM switching circuit. The circuit can be designed to provide purely active power conversion of a band-limited input voltage source to a DC load. 


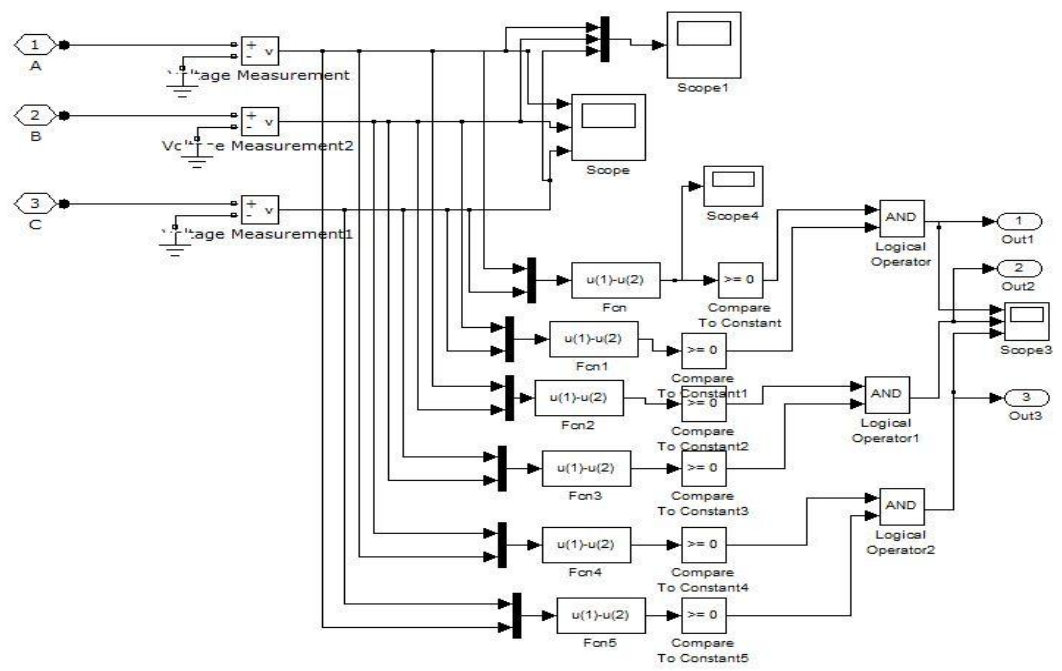

Fig.8. Simulation of Gate pulse generation according to Table
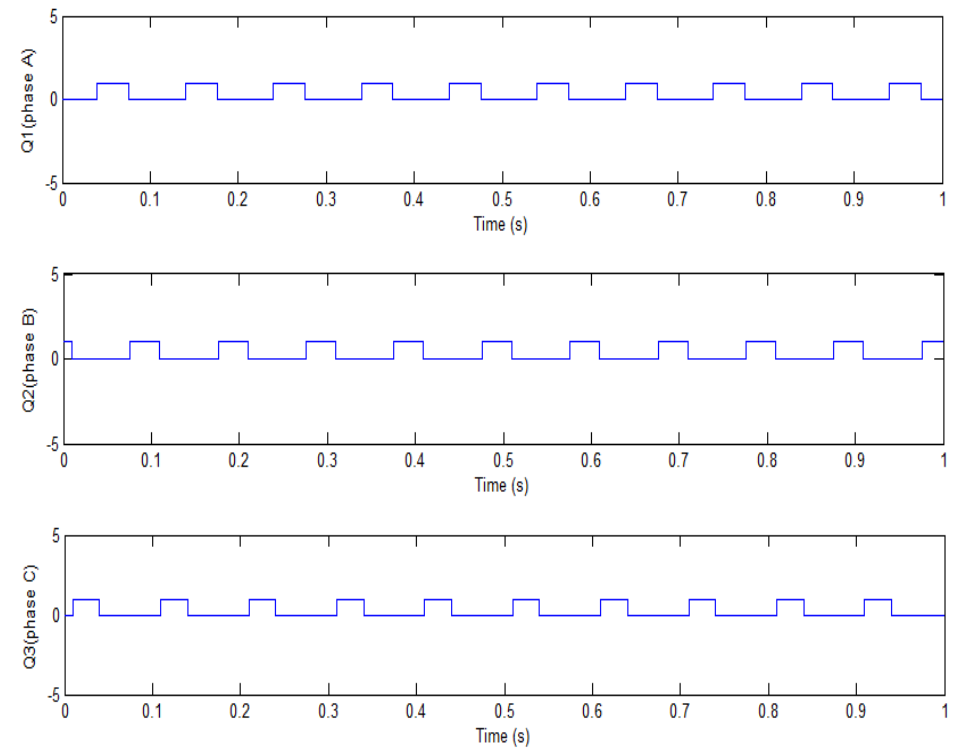

Fig.9.Gate pulse for three switches

The above figure shows the gate pulse, among the three switches exactly one switch is on at a time.

\section{B. Simulation of ac-dc converter}

The simulation result for ac-dc boost converter with respect to gate pulse according to the switching state of three switches were developed using the SIMELECTRONICS toolbox of MATLAB with the following parameters:

TABLE. II.

PARAMETER TABLE

\begin{tabular}{|c|c|}
\hline PARAMETERS & SPECIFICATIONS \\
\hline $\mathrm{L}$ & $0.49 \mathrm{mH}$ \\
\hline $\mathrm{C}$ & $100 \mu \mathrm{F}$ \\
\hline Battery Voltage $\left(\mathrm{V}_{\mathrm{B}}\right)$ & $12 \mathrm{~V}$ \\
\hline $\mathrm{V}_{\mathrm{D}}$ & $0.6 \mathrm{~V}$ \\
\hline $\mathrm{f}_{\mathrm{j}}$ & $10 \mathrm{~Hz}$ \\
\hline $\mathrm{f}_{\mathrm{s}}$ & $1 \mathrm{kHz}$ \\
\hline
\end{tabular}

Here $f_{i} \& f_{s}$ are the frequencies of the three-phase input signal and PWM control signal respectively. It should be noted that $\mathrm{f}_{\mathrm{i}}$ is considered as low as $10 \mathrm{~Hz}$ to evaluate the performance of the converter for applications involving energy harvesting from energy sources with a low-frequency content input waveform, e.g., vehicle suspension systems, low-speed wind turbines, and electric bike regenerative systems. 


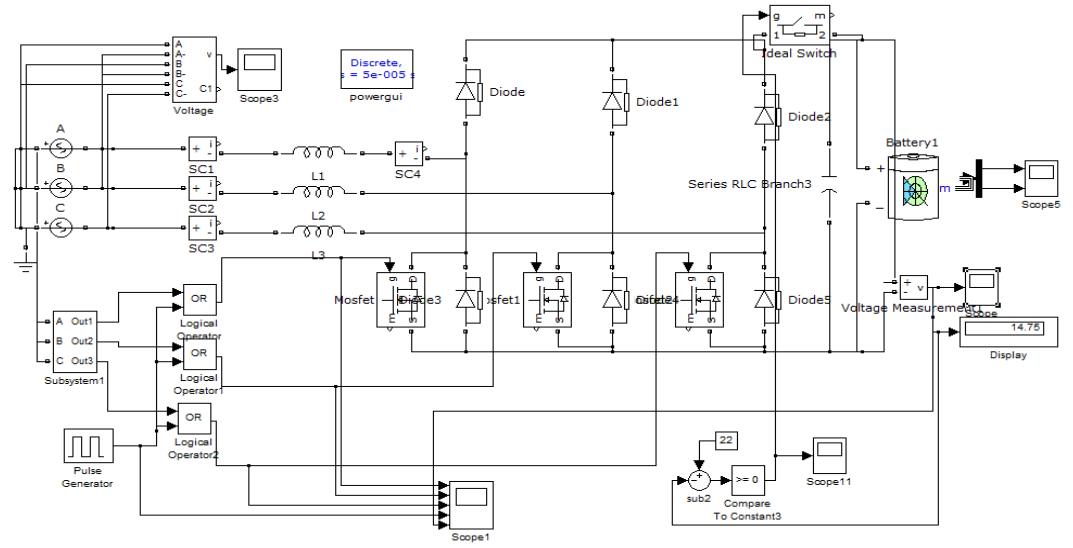

Fig.10. Simulation for ac-dc boost converter

The main simulation diagram of three phase ac-dc boost converter is shown in fig.9. According to gate pulse generating circuit, the duty cycle can be adjusted in pulse generator.

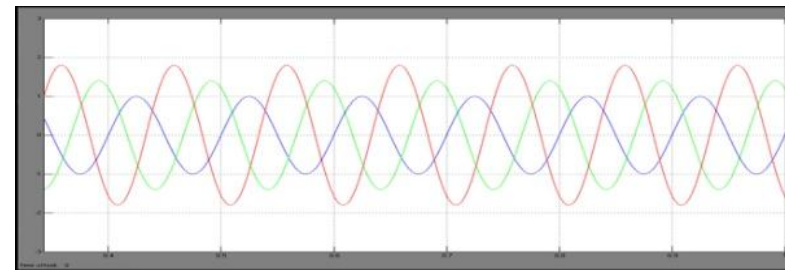

Fig.11. variable input waveform

Fig.10. shows that the input is variable in amplitude which is given as a source to the boost converter.The irregular power signal does not have at least one of the following: a sinusoidal steady state, fixed amplitude, or a fixed frequency.

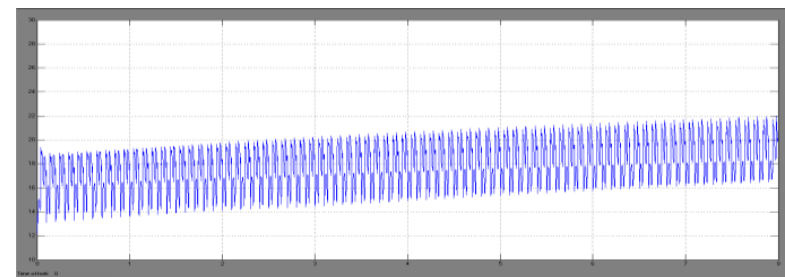

Fig.12. charging of battery

The battery was charging even when the input voltage is very low. The battery can be charged until it reaches the maximum charging capacity.

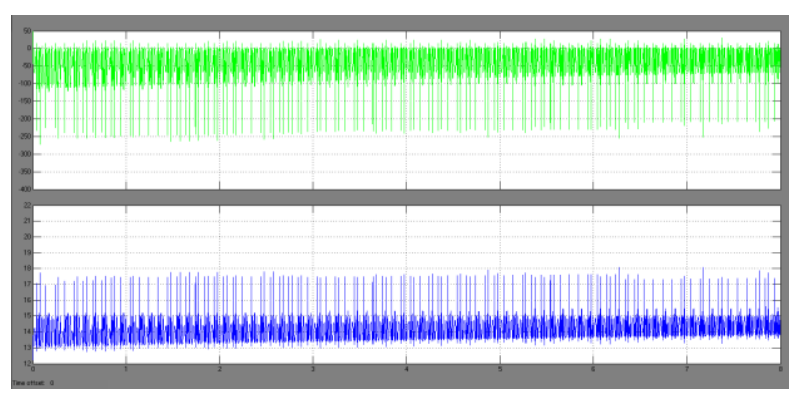

Fig.13. Battery voltage \& current

In above figure the first graph denotes the current of the battery and second graph denotes the voltage of the battery. In battery the current and voltage are in opposite direction. 


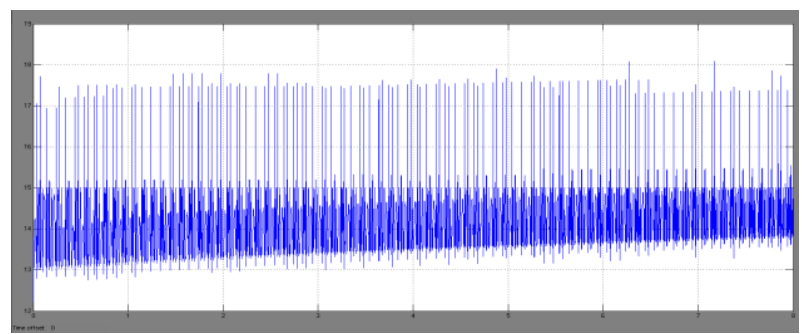

Fig.14. Maximum capacity of battery

Fig.13. represents that the charging of battery should not exceed the maximum capacity of battery even when the variable input voltage in high range.

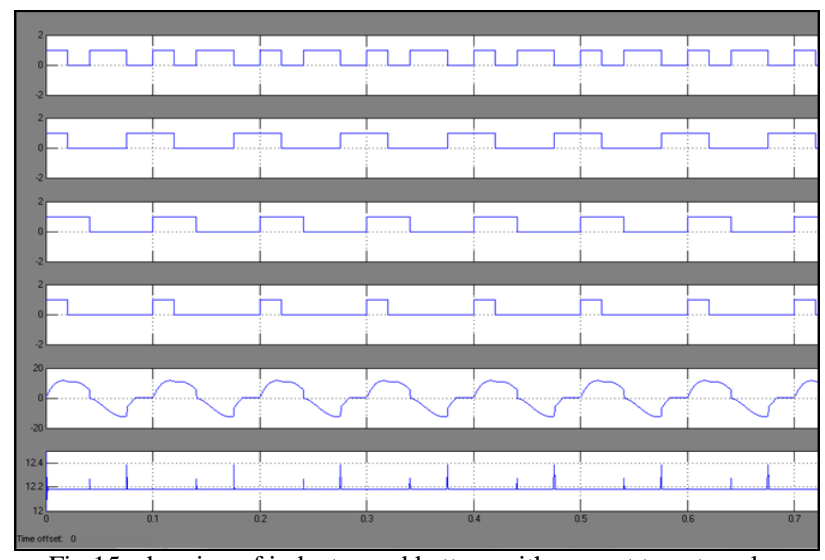

Fig.15. charging of inductor and battery with respect to gate pulse

The above figure shows the charging of inductor and battery for $20 \%$ of duty cycle with respect to gate pulse. Hence the power can be transferred from irregular input source to battery efficiently.

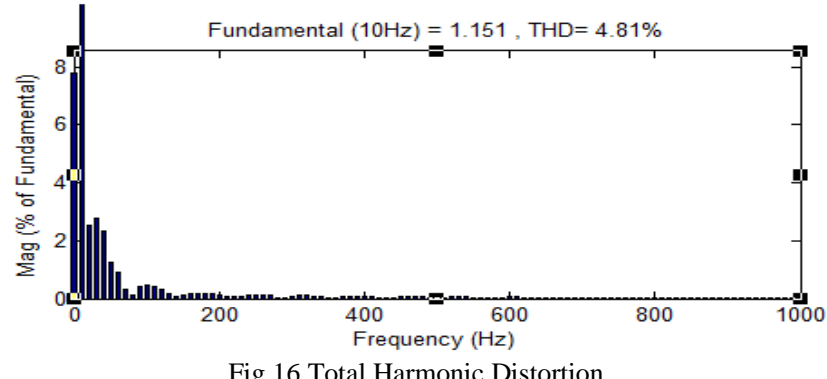

The above figure shows that harmonics can be very small in this converter so the active power can be transferred from variable source to DC link.

\section{Conclusion}

In this paper, analytical expressions describing the input characteristic of a three-phase boost-type converter were derived, based on that the range of the duty cycle can be obtained. According to the switching states of three modes, the gate signal can be generated. With respect to gate signal \& range of duty cycle, the boost converter charges the battery and hence the maximum power can be transferred to battery storage device or a DC link. The resistive input behavior can greatly reduce harmonic components and improve power quality. This scheme is not based on the sinusoidal steady state conditions, so this can be applicable to low speed wind turbines, wave energy converters and mechanical vibrations for converting mechanical energy into stand-alone or grid connected electricity. The phase to phase input resistance has a bias term and, a non-linear term which are compensated via feedback controller. This feature is attractive in several renewable energy conversion systems such as low speed wind, wave energy conversion, and regenerative suspension and braking in electric vehicle applications. In future the control algorithm and switching scheme may be extended to high power converters. 


\section{References}

[1] B.Singh, B.N.Singh, A.Chandra, K.Al-Haddad, A.Pandey, and D.P.Kothari, "A review of three-phase improved power quality ACDC converters, IEEETrans.Ind. Electron" vol.51, no.3, pp.641-660, Jun.2004.

[2] S. Choi, "A three-phase unity-power-factor diode rectifier with active input current shaping," IEEE Trans. Ind. Electron., vol. 52, no. 6, pp. 1711-1714, Dec. 2007.

[3] G.Gong, M.L.Heldwein, U.Drofenik, J.Minibock, K.Mino, and J.W.Kolar, "Comparative evaluation of three-phase high-powerfactor AC-DC converter concepts for application in future more electric air- craft, "IEEETrans.Ind.Electron.,vol.52,no.3,pp.727737,Jun.2005.

[4] X. Du, L. Zhou, H. Lu, and H.-M. Tai, "DC link active power filter for three-phase diode rectifier," IEEE Trans. Ind. Electron., vol. 59, no. 3, pp. 1430-1442, Mar. 2012.

[5] T.Nussbaumer and J.W.Kolar, "Improving mains current quality for three-phase three-switch buck-type PWM rectifiers, "IEEETrans.Power Electron.,vol.21,no.4,pp.967-973,Jul.2006.

[6] V.F.Pires and J.F.Silva, "Three-phase single-stage four-switch PFC buck-boost-type rectifier, "IEEE Trans.Ind.Electron., vol.52,no.2, pp.444-453,Apr.2005.

[7] S. K. Mazumder, "A novel discrete control strategy for independent stabilization of parallel three-phase boost converters by combining space vector modulation with variable-structure control," IEEE Trans. Power Electron., vol. 18, no. 4, pp. 1070-1083, Jul. 2003.

[8] R. Garcia-Gil, J. M. Espi, E. J. Dede, and E. Sanchis-Kilders, “A bidirectional and isolated three-phase rectifier with soft-switching operation," IEEE Trans. Ind. Electron., vol. 52, no. 3, pp. 765-773, Jun. 2005.

[9] J.F.Silva, "Sliding-mode control of boost-type unity-power-factor PWM rectifiers,"IEEE Trans.Ind. Electron.,vol. 46, no. 3, pp. 594-603, Jun.1999.

[10] A. Lidozzi, L. Solero, and F. Crescimbini, "Adaptive direct-tuning control for variable-speed diesel-electric generating units," IEEE Trans. Ind. Electron., vol. 59, no. 5, pp. 2126-2134, May 2012.

[11] T.S.Lee, "Input-output linearization and zero-dynamics control of three phase AC/DC voltage-source converters," IEEE Trans. Power Electronics., vol.18, no.1, pp. 11-22, Jan. 2003.

[12] M. Kesraoui, N. Korichi, and A. Belkadi, "Maximum power point tracker of wind energy conversion system," Renew. Energy, vol. 36, no. 10, pp. 2655-2662, Oct. 2011. 